\title{
MAXIMAL AND EXPLOSIVE STRENGTH NORMATIVE DATA FOR HANDGRIP TEST ACCORDING TO GENDER: INTERNATIONAL STANDARDIZATION APPROACH
}

original paper

( ) Wroclaw University of Health and Sport Sciences

DOI: https://doi.org/10.5114/hm.2022.108314

\section{MILIVOJ DOPSAJ ${ }^{1,2}{ }^{\oplus}$, ZAHI ANDRAOS $^{1,3}{ }^{\oplus}$, CHARBEL RICHA $^{1 \oplus}$, ANTOINE ABOU MITRI $^{1,4}$, ELIE MAKDISSI $^{1,4}{ }^{\oplus}$, ALLEN EL ZOGHBI $^{1,4}{ }^{\oplus}$, RAFIF DANDACHI $^{1,4}{ }^{\oplus}$, VADIM V. ERLIKH $^{2}$, EVGENII A. CHEREPOV ${ }^{2}{ }^{\oplus}$, NERIUS MASIULIS ${ }^{5}{ }^{\circledR}$, ANNA V. NENASHEVA $^{2 \oplus}$, ILONA J. ZUOZIENE ${ }^{6 \oplus}$, STEFAN MARKOVIĆ $^{1 \oplus}$, FADI FAYYAD ${ }^{1,7}$ (®}

\footnotetext{
${ }^{1}$ Faculty of Sport and Physical Education, University of Belgrade, Belgrade, Serbia

${ }^{2}$ Institute of Sport, Tourism and Service, South Ural State University, Chelyabinsk, Russia

${ }^{3}$ Faculty of Sport Sciences, Antonine University, Baabda, Lebanon

${ }^{4}$ Department of Physical Education and Sport, Faculty of Education, Lebanese University, Beirut, Lebanon

${ }^{5}$ Department of Health Promotion and Rehabilitation, Lithuanian Sports University, Kaunas, Lithuania

${ }^{6}$ Department of Sports Coaching Science, Lithuanian Sports University, Kaunas, Lithuania

${ }^{7}$ Modern University for Business and Science, Beirut, Lebanon
}

\begin{abstract} for external validation.

\section{Introduction}

The human hand is one of the most distinctive organs of humankind in terms of interaction with the environment. Also, it plays a primary role in the successful evolution of humans [1]. In daily life, hands are the basic organs for manipulative tasks of the human body, and they are specialized for various motor skills to interact with physical objects [2]. This is the biologi-
\end{abstract}

Purpose. In daily living, hands are the basic organs for manipulative tasks of the human body, and they are specialized for various motor tasks with different physical object contact situations. Insufficient strength during aging constitutes a key component of sarcopenia and is associated with subsequent disability and mortality. The simplest and very valid test for assessing general strength is the handgrip test, and the need for international standards for grip strength seems very essential. The study aimed to set normative data for different handgrip strength dimensions in an international healthy adult community. Methods. The maximal muscle force and maximal explosive muscle force for dominant and non-dominant hand were examined across 838 subjects from 11 countries. The result values were compared with the internationally published findings

Results. The mean value for both hands maximal strength in an adult male was $997 \pm 176 \mathrm{~N}$ for the absolute and $11.78 \pm$ $1.95 \mathrm{~N} / \mathrm{kg}$ for the relative measure; in females, the respective values equalled $550 \pm 110 \mathrm{~N}$ and $8.49 \pm 1.79 \mathrm{~N} / \mathrm{kg}$. The mean value for maximal explosive strength in an adult male was $6473 \pm 1420 \mathrm{~N} / \mathrm{s}$ for the absolute and $76.47 \pm 16.22 \mathrm{~N} / \mathrm{s} / \mathrm{kg}$ for the relative measure; in adult females, the respective values equalled $3506 \pm 915 \mathrm{~N} / \mathrm{s}$ and $54.13 \pm 14.38 \mathrm{~N} / \mathrm{s} / \mathrm{kg}$.

Conclusions. The normative reference values provided in this study may serve as an international guide for interpreting maximal and explosive handgrip strength measurements obtained from healthy adult individuals of both genders.

Key words: handgrip, maximal strength, explosive strength, international standards, normative values

cal reason why the handgrip movement and achieved strength dimensions are recognized as a limiting factor in all the manipulative activities by the upper part of the body, regardless of whether this refers to daily activities, work and the professional environment, or sports [3-5].

The hand uses a mechanism to grab handles and large heavy tools with the power grip, whereby all fingers are flexed around objects [2]. The power grip is

Correspondence address: Fadi Fayyad, Athletic Department, Modern University for Business and Science, Beirut, 113-7501, Lebanon, e-mail: fadiify@hotmail.com, https://orcid.org/0000-0003-4516-3156

Received: July 2, 2020

Accepted for publication: March 14, 2021

Citation: Dopsaj M, Andraos Z, Richa C, Mitri AA, Makdissi E, El Zoghbi A, Dandachi R, Erlikh VV, Cherepov EA, Masiulis N, Nenasheva AV, Zuoziene IJ, Marković S, Fayyad F, Maximal and explosive strength normative data for handgrip test according to gender: international standardization approach. Hum Mov. 2022;23(4):77-87; doi: https://doi.org/10.5114/hm.2022.108314. 
the most primitive but also the most powerful grasping movement, which makes it a very convenient position for testing, especially for arms and cranial parts of the body. Because of that, the handgrip strength is a well-known test which can be easy to use for different population samples [3, 4, 6-9]. Besides that, handgrip strength dimensions have been recognized as valuable biomarkers of general health status, and they have been recommended as valid indicators of overall muscle body strength, independent of age and gender [10-16].

The following 2 dimensions of isometric muscle strength are considered as the most representative mechanical contractile characteristics: maximal isometric muscle force $\left(\mathrm{F}_{\max }\right)$ and maximal isometric rate of force development $\left(\mathrm{RFD}_{\max }\right)[5,17,18]$. Both of them are enumerated among the most important muscle contractile dimensions considering measurements of physical abilities, regardless of whether referring to healthy people, people with certain health risk, or athletes $[4,7,8,12,14,16]$.

The mentioned mechanical contractile characteristics can be easily evaluated by applying the maximum handgrip test, as a highly reliable, valid, easy to administer, and widely utilized useful testing tool in the general adult population, as a robust marker of aging and general health status [12, 19, 20].

Given all the previously mentioned advantages, and with a very simple measurement procedure, the handgrip test is mostly applied in population studies, especially in population-based cross-sectional studies, to describe muscular fitness during aging, using agegroup standards and normative values [21-24].

However, all population studies already published have defined normative standards with internal validation of data, i.e. only with the national population. The second concept of the mentioned studies involved only one muscular dimension, i.e. maximal strength $\left(\mathrm{F}_{\max }\right)$. Unfortunately, maximal explosiveness $\left(\mathrm{RFD}_{\max }\right)$, for which there are scientific facts considering health and life well-being effects, has no defined standards yet $[7,25]$. Also, the following benefits associated with $\mathrm{RFD}_{\max }$ can be recognized as important functional consequences as the characteristic determines the force that can be generated in the early phase of muscle contraction (0-200 ms). According to the recently published research, it seems that RFD is better related to performance in sports-specific and daily task functioning and more sensitive than $\mathrm{F}_{\max }$ to detect chronic and acute changes in neuromuscular function, which can be essential for a researcher in sports sciences and human exercise physiology, as well as for practice in the field of rehabilitation, health, aging, and physical training $[7,18]$.

Besides, it is very important for sports performance because it has been used to evaluate the capacity to rapidly generate muscular force, and it is a determinant of the neural factor of muscle contraction [17].

Since it is known that lack of optimal strength is a key component of sarcopenia and is associated with subsequent disability and mortality, the need for international specific standards for handgrip strength dimensions from a health prevention diagnostics point of view seems to be very essential. For these reasons, the study aimed to set normative data for different handgrip strength dimensions $\left(\mathrm{F}_{\max }\right.$ and $\left.\mathrm{RFD}_{\max }\right)$ for healthy adults of both genders on the international level of standards.

\section{Material and methods}

\section{Study design}

The research was conducted via a multicentre retrospective cohort study while applying laboratory and field testing procedures. The direct measurement was used with an isometric testing protocol $[4,5,8]$. All measurements were made with the same equipment by the same researchers and under the same testing procedures during the period of 2016-2020. The research followed the Declaration of Helsinki [26].

\section{Subject sample}

In this research, we analysed the results of a handgrip test conducted in a sample of 838 subjects from 11 countries (Croatia: $n=27$, Cyprus: $n=18$, Germany: $n=21$, Hungary: $n=29$, Italy: $n=15$, Lebanon: $n=19$, Lithuania: $n=54$, Russia: $n=219$, Serbia: $n=326$, Slovenia: $n=96$, Spain: $n=14)$. The general descriptive data of the sample were as follows. For males $(n=444)$ : age: $37.0 \pm 14.0$ years, body height: $182.0 \pm$ $7.0 \mathrm{~cm}$, body mass: $85.5 \pm 13.0 \mathrm{~kg}$, body mass index: $26.0 \pm 4.0 \mathrm{~kg} / \mathrm{m}^{2}$. For females $(n=394)$ : age: $37.0 \pm$ 13.0 years, body height: $168.0 \pm 7.0 \mathrm{~cm}$, body mass: $66 \pm 12.0 \mathrm{~kg}$, body mass index: $23.0 \pm 4.0 \mathrm{~kg} / \mathrm{m}^{2}$.

All respondents were healthy adult individuals from the general population. They were informed about the purpose of the study and voluntarily accepted to be involved in the study. Participants were excluded if they were suffering from an injury at the time of handgrip assessment, had undergone any arm or hand injury 
within the previous 6 months, or had undergone surgery of either hand or wrist in the previous year. Also, non-communicable diseases and hormonal disorders were among the exclusion criteria.

\section{Testing procedure}

The handgrip isometric test protocol was carried out with standardized procedures and equipment, i.e. a handgrip device (Figure 1) with a fixed strain gauge (Sports Medical Solutions, All4gym d.o.o., Serbia) was used to measure the mechanical characteristics of isometric handgrip strength [20]. During the test, the subjects were sitting upright in the middle of a chair with an extended arm and holding the measuring device in the tested hand, in accordance with the procedure explained in previously published literature $[4,5,7,20,27]$. The earlier published results have shown that the applied handgrip test is highly reliable, with the intraclass correlation coefficient ranging 0.938 0.977 for $\mathrm{F}_{\max }$ and 0.903-0.971 for $\mathrm{RFD}_{\max }$ [27].

Before the handgrip testing procedures, verbal explanation was given; each examinee performed 2 pretrial familiarization measurements, alternating the hands randomly, at a moderate effort. After a 2-minute rest, the handgrip test was carried out. The power grip, as the strongest grip, was used. The subjects were asked to exert the strongest and quickest possible pressure on the device on the researcher's sign, holding the grip for a minimum of 2 seconds, while the verbal encour- agement was provided [5, 20,27]. The handgrip test of the dominant and non-dominant hand was conducted twice (in a randomized order), with a 1-minute interval between the trials. During the testing, the participants were instructed to keep their arms by their side, and the tested arm was placed in the slightly abducted position (approximately 5-10 cm), without touching the body or the chair.

$\mathrm{F}_{\max }$ and $\mathrm{RFD}_{\max }$ were recorded from each trial using a laptop computer. The maximal force was assessed through the maximum of the achieved muscle force level $\left(\mathrm{F}_{\max }\right)$, and $\mathrm{RFD}_{\max }$ was calculated as the maximal slope of the force-time curve (over the first derivative of the force-time curve) with regard to the force onset [5, 28]. The onset of the contraction was defined as the point in time when the first derivative of the force-time curve exceeded the baseline by $3 \%$ of its maximal value. The strain gauge used in the handgrip test was connected to a force reader with the precision of $\pm 0.1 \mathrm{~N}$. The force-time signal was sampled at $500 \mathrm{~Hz}$ (i.e. 500 samples per second) and low-pass filtered $(10 \mathrm{~Hz})$ with a fourth-order (zero-phase lag) Butterworth filter, and $\mathrm{RFD}_{\max }$ was calculated with the method of the instantaneous slope of force-time relation considering the measurement time interval [5, 28].

A software-hardware system specially designed for isometric measurement (Sports Medical Solutions Isometrics, ver. 3.4.0) was used for data collection and processing. All test results for variables were recorded

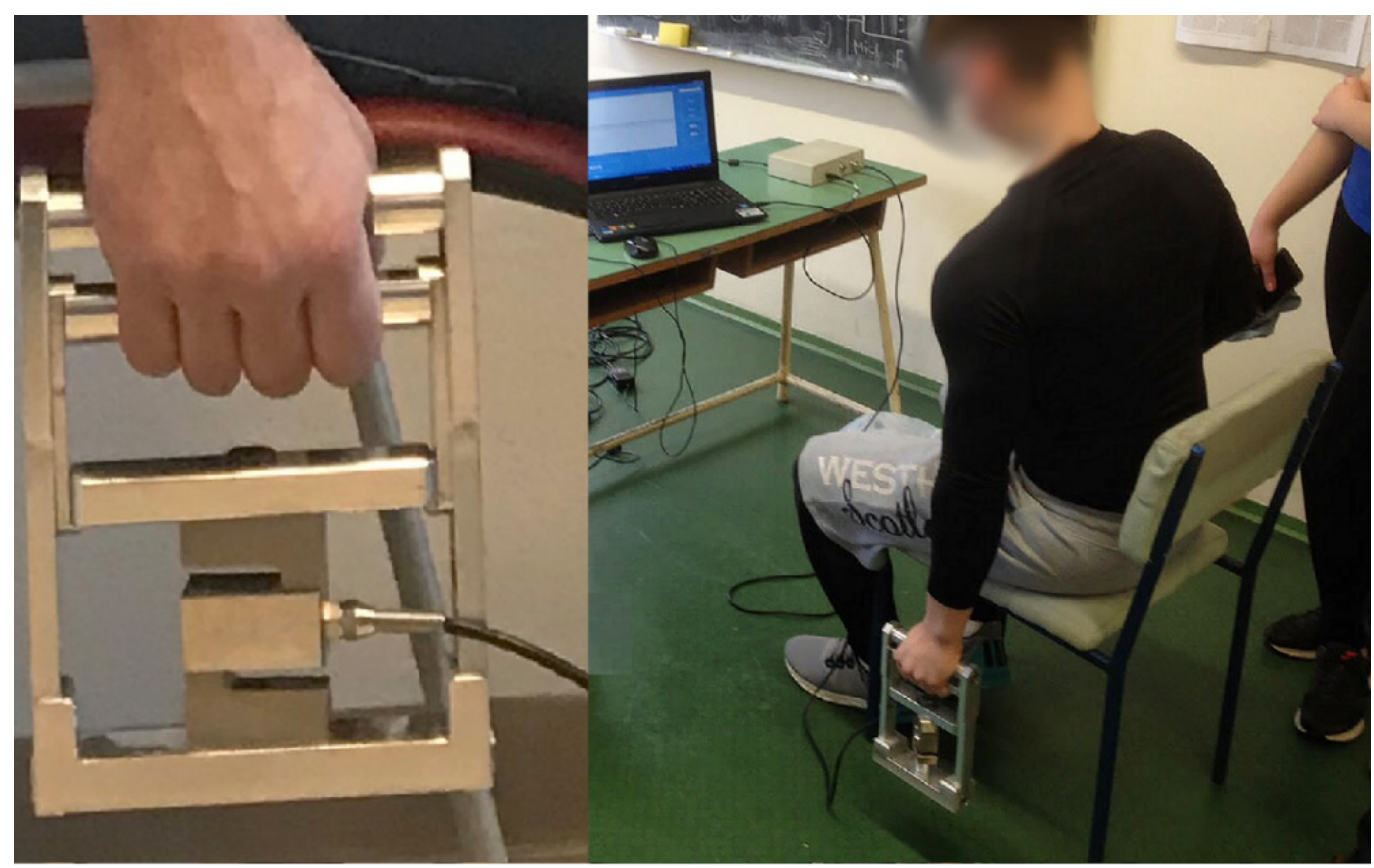

Figure 1. Sports Medical Solutions handgrip device with a fixed strain gauge 
in a specialized database, and the better result was used for data processing and statistical analysis.

\section{Variables}

As most representative handgrip variables, we used the following, expressed in absolute and relative aspects.

Variables for maximal mechanical force dimensions, considering the absolute aspect, were:

1. $\mathrm{F}_{\max \_} \mathrm{D}, \mathrm{F}_{\max \_} \mathrm{ND}$, and $\mathrm{F}_{\max -} \mathrm{SUM}$ : maximal muscle force for the dominant (D) and non-dominant (ND) hand, and summarized (SUM) value of maximal muscle force for the D and ND hand, expressed in newtons $(\mathrm{N})$.

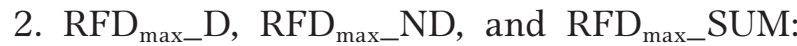
maximal explosive muscle force for the $\mathrm{D}$ and $\mathrm{ND}$ hand, and summarized (SUM) value of maximal explosive muscle force for the D and ND hand, expressed in newtons per second $(\mathrm{N} / \mathrm{s})$.

Variables for maximal mechanical force dimensions, considering the relative aspect, were:

3. $\mathrm{F}_{\text {rel_}} \mathrm{D}, \mathrm{F}_{\mathrm{rel} \_} \mathrm{ND}$, and $\mathrm{F}_{\text {rel_}} \mathrm{SUM}$ : relative aspects of maximal muscle force for the D and ND hand, and summarized (SUM) value for the D and ND hand, expressed in newtons per kilogram of body mass $(\mathrm{N} / \mathrm{kg})$.

4. $\mathrm{RFD}_{\text {rel_}} \mathrm{D}, \mathrm{RFD}_{\text {rel_}} \mathrm{ND}$, and $\mathrm{RFD}_{\text {rel_}} \mathrm{SUM}$ : relative aspects of maximal explosive muscle force for the D and ND hand, and summarized (SUM) value for the D and ND hand, expressed in newtons per second per kilogram of body mass $(\mathrm{N} / \mathrm{s} / \mathrm{kg})$.

\section{Statistical procedures}

For all variables, basic descriptive statistics were calculated: mean value, standard deviation, and coefficient of variation, as central tendency measures and dispersion of raw data. For the real range of data, minimal and maximal values are shown, while for defining critical ranges for the observed data, the 95\% confidence interval for mean with lower and upper bound reference line was calculated. Because of the multicentre nature of the study, the accuracy of overall measurement procedures was calculated with the absolute value of the standard error of the mean. For normative values, 2 different metrological procedures were used: calculation 7D metrological procedures and percentile distribution standards [29, 30]. All statistical analyses were carried out with the SPSS Win Statistics 23.0 software package, with the probability level of $95 \%$ and a $p$-value of 0.05 [31].

\section{Ethical approval}

The research related to human use has complied with all the relevant national regulations and institutional policies, has followed the tenets of the Declaration of Helsinki, and has been approved by the Ethical Committee of the Faculty of Sport and Physical Education, University of Belgrade, under the number of 484-2.

\section{Informed consent}

Informed consent has been obtained from all individuals included in this study.

\section{Results}

In Table 1, descriptive data are shown for the explored variables, depending on gender. Table 2 presents the calculated international handgrip standards for the observed variables for each gender. Figures 2 and 3 depict the boxplot distribution for the absolute and relative values, respectively, of maximal muscle force and maximal explosive muscle force for male and female subjects. Table 3 presents the percentile standards for handgrip muscle force by gender. In Figures $4-7$, external validation data for $\mathrm{F}_{\max } \mathrm{SUM}$ and $\mathrm{RFD}_{\text {max }} \mathrm{SUM}$ for male and female subjects are shown for comparison of the actual results with those of other published studies that used the same method of measurement.

\section{Discussion}

The study demonstrated (Table 1) that the mean value for maximal handgrip strength for an adult male was $997 \pm 176 \mathrm{~N}$ (512.4 and 484.5 for the dominant and non-dominant hand, respectively), considering the absolute measure, and $11.78 \pm 1.95 \mathrm{~N} / \mathrm{kg}(6.1$ and 5.7 for the dominant and non-dominant hand, respectively) as a relative measure. As for the explosive strength, for an adult male, the mean value for maximal explosive handgrip strength was $6473 \pm 1420 \mathrm{~N} / \mathrm{s}$ (3347.7 and 3124.9 for the dominant and non-dominant hand, respectively) as an absolute and $76.47 \pm$ $16.22 \mathrm{~N} / \mathrm{s} / \mathrm{kg}$ (39.5 and 36.9 for the dominant and nondominant hand, respectively) as a relative measure. Regarding the female results, the mean value for maximal handgrip strength was $550 \pm 110 \mathrm{~N}$ (284.1 and 265.8 for the dominant and non-dominant hand, respectively), considering the absolute measure, and 8.49 $\pm 1.79 \mathrm{~N} / \mathrm{kg}$ (4.4 and 4.1 for the dominant and nondominant hand, respectively) as a relative measure. As for the explosive strength, it was observed that the 
Table 1. Descriptive data for the explored variables by gender

\begin{tabular}{|c|c|c|c|c|c|c|c|c|c|}
\hline \multicolumn{2}{|c|}{ Variables } & Mean & $S D$ & CV\% & SEM & $\begin{array}{c}95 \% \text { CI } \\
\text { lower bound }\end{array}$ & $\begin{array}{c}95 \% \text { CI } \\
\text { upper bound }\end{array}$ & Min & Max \\
\hline \multicolumn{10}{|l|}{ Males } \\
\hline \multirow{3}{*}{$\begin{array}{l}\mathrm{F}_{\max } \\
(\mathrm{N})\end{array}$} & $\mathrm{D}$ & 512.4 & 95.1 & 18.6 & 4.5 & 503.5 & 521.2 & 221.0 & 859.0 \\
\hline & ND & 484.5 & 86.9 & 17.9 & 4.1 & 476.4 & 492.6 & 238.0 & 821.0 \\
\hline & SUM & 997.0 & 176.0 & 17.6 & 8.3 & 981.0 & 1013.0 & 532.0 & 1680.0 \\
\hline \multirow{3}{*}{$\begin{array}{l}\mathrm{RFD}_{\max } \\
(\mathrm{N} / \mathrm{s})\end{array}$} & $\mathrm{D}$ & 3347.7 & 757.5 & 22.6 & 35.9 & 3277.1 & 3418.4 & 782.0 & 5572.0 \\
\hline & ND & 3124.9 & 716.9 & 22.9 & 34.0 & 3058.0 & 3191.7 & 955.0 & 5267.0 \\
\hline & SUM & 6473.0 & 1420.0 & 21.9 & 67.4 & 6340.0 & 6605.0 & 1737.0 & $10,645.0$ \\
\hline \multirow{3}{*}{$\begin{array}{l}\mathrm{F}_{\text {rel }} \\
(\mathrm{N} / \mathrm{kg})\end{array}$} & $\mathrm{D}$ & 6.1 & 1.0 & 16.4 & 0.1 & 5.9 & 6.1 & 3.0 & 9.3 \\
\hline & ND & 5.7 & 1.0 & 17.5 & 0.1 & 5.6 & 5.8 & 2.8 & 8.8 \\
\hline & SUM & 11.8 & 1.9 & 16.5 & 0.1 & 11.6 & 12.0 & 6.2 & 17.8 \\
\hline \multirow{3}{*}{$\begin{array}{l}\mathrm{RFD}_{\text {rel }} \\
(\mathrm{N} / \mathrm{s} / \mathrm{kg})\end{array}$} & $\mathrm{D}$ & 39.5 & 8.6 & 21.8 & 0.4 & 38.7 & 40.3 & 9.5 & 63.4 \\
\hline & ND & 36.9 & 8.3 & 22.5 & 0.4 & 36.1 & 37.7 & 11.7 & 60.6 \\
\hline & SUM & 76.5 & 16.2 & 21.2 & 0.8 & 75.0 & 78.0 & 21.2 & 124.0 \\
\hline \multicolumn{10}{|l|}{ Females } \\
\hline \multirow{3}{*}{$\begin{array}{l}\mathrm{F}_{\max } \\
(\mathrm{N})\end{array}$} & $\mathrm{D}$ & 284.1 & 57.0 & 20.1 & 2.9 & 278.4 & 289.7 & 115.0 & 530.0 \\
\hline & ND & 265.8 & 57.7 & 21.7 & 2.9 & 260.0 & 271.4 & 122.0 & 491.0 \\
\hline & SUM & 550.0 & 110.0 & 20.0 & 5.5 & 539.0 & 561.0 & 259.0 & 1010.0 \\
\hline \multirow{3}{*}{$\begin{array}{l}\mathrm{RFD}_{\max } \\
(\mathrm{N} / \mathrm{s})\end{array}$} & $\mathrm{D}$ & 1858.3 & 500.7 & 26.9 & 21.6 & 1776.6 & 1940.1 & 488.0 & $15,016.0$ \\
\hline & ND & 1681.7 & 434.5 & 25.8 & 23.4 & 1635.7 & 1727.7 & 552.0 & 3537.0 \\
\hline & SUM & 3506.0 & 915.0 & 26.1 & 46.1 & 341.0 & 3596.0 & 1148.0 & 7790.0 \\
\hline \multirow{3}{*}{$\begin{array}{l}\mathrm{F}_{\mathrm{rel}} \\
(\mathrm{N} / \mathrm{kg})\end{array}$} & $\mathrm{D}$ & 4.4 & 0.9 & 20.5 & 0.1 & 4.3 & 4.5 & 1.7 & 7.0 \\
\hline & ND & 4.1 & 0.9 & 21.9 & 0.1 & 4.0 & 4.2 & 1.4 & 6.6 \\
\hline & SUM & 8.5 & 1.8 & 21.1 & 0.1 & 8.3 & 8.7 & 3.9 & 13.3 \\
\hline \multirow{3}{*}{$\begin{array}{l}\mathrm{RFD}_{\text {rel }} \\
(\mathrm{N} / \mathrm{s} / \mathrm{kg})\end{array}$} & $\mathrm{D}$ & 28.7 & 7.5 & 26.1 & 0.6 & 27.4 & 29.6 & 7.3 & 50.1 \\
\hline & ND & 26.0 & 7.0 & 26.9 & 0.4 & 25.3 & 26.7 & 6.4 & 48.6 \\
\hline & SUM & 54.1 & 14.4 & 26.6 & 0.7 & 52.7 & 55.6 & 17.1 & 102.9 \\
\hline
\end{tabular}

$S D$ - standard deviation, CV\% - coefficient of variation, SEM - standard error of the mean, CI - confidence interval, $\mathrm{F}_{\max }$ - maximal muscle force, $\mathrm{RFD}_{\max }$ - maximal explosive muscle force, $\mathrm{F}_{\mathrm{rel}}$ - relative aspect of maximal muscle force, $\mathrm{RFD}_{\text {rel }}$ - relative aspect of maximal explosive muscle force, D - dominant hand, ND - non-dominant hand, SUM - summarized for both hands
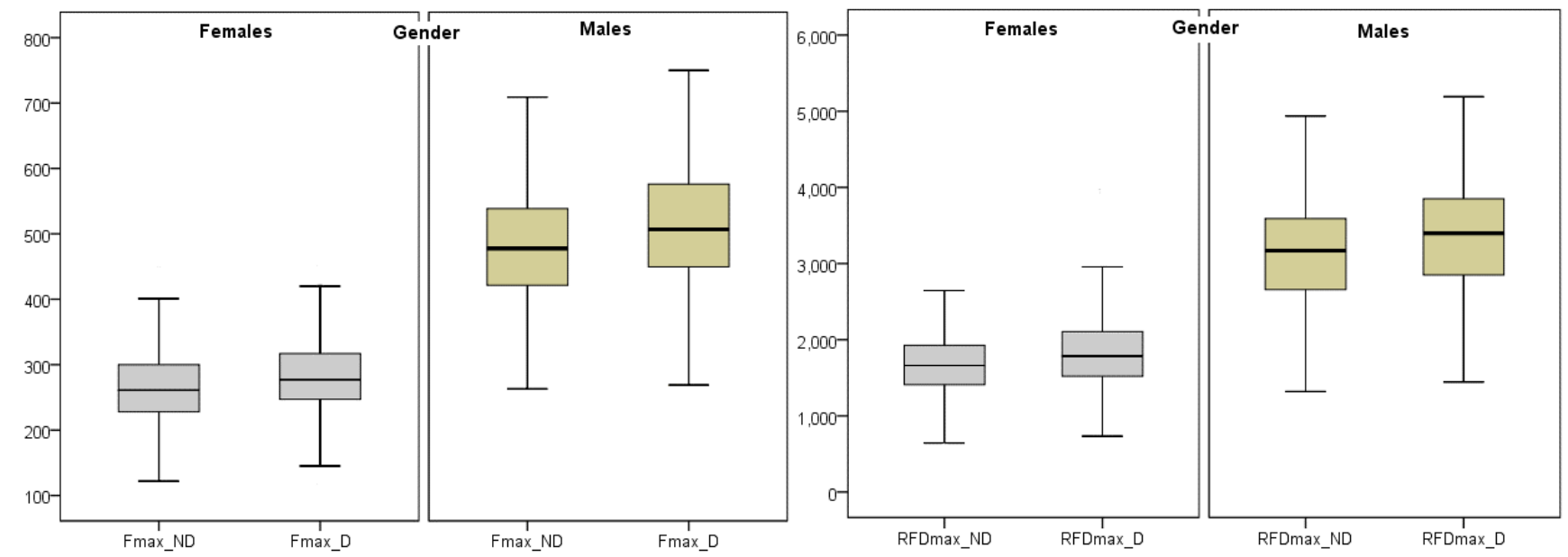

Figure 2. Boxplot distribution for maximal muscle force $\left(\mathrm{F}_{\max }\right)$ and maximal explosive muscle force $\left(\mathrm{RFD}_{\max }\right)$ for the dominant (D) and non-dominant (ND) hand among male and female subjects 


\section{HUMAN MOVEMENT}

M. Dopsaj et al., Global handgrip test normative data

Table 2. Handgrip muscle strength normative standards for the observed variables by gender

\begin{tabular}{|c|c|c|c|c|c|c|c|c|}
\hline Varia & & Superior & Excellent & $\begin{array}{c}\text { Above } \\
\text { standard }\end{array}$ & $\begin{array}{l}\text { Standard } \\
\text { values }\end{array}$ & $\begin{array}{c}\text { Below } \\
\text { standard }\end{array}$ & Poor & Very poor \\
\hline Males & & & & & & & & \\
\hline & $\mathrm{D}$ & $\geq 703$ & $702-607$ & $606-560$ & 559-465 & $464-417$ & $416-322$ & $\leq 321$ \\
\hline $\begin{array}{l}F_{\max } \\
\text { (N) }\end{array}$ & ND & $\geq 658$ & $657-571$ & 570-528 & $527-441$ & $440-398$ & 397-311 & $\leq 310$ \\
\hline & SUM & $\geq 1349$ & 1173-1348 & 1085-1172 & 910-1084 & $821-909$ & $646-820$ & $\leq 645$ \\
\hline & $\mathrm{D}$ & $\geq 4863$ & $4862-4105$ & $4104-3726$ & $3725-2969$ & $2968-2590$ & $2589-1833$ & $\leq 1832$ \\
\hline & ND & $\geq 4559$ & $4558-3842$ & $3841-3483$ & $3482-2766$ & $2765-2408$ & $2407-1691$ & $\leq 1690$ \\
\hline & SUM & $\geq 9314$ & 7894-9313 & 7183-7893 & 5763-7182 & 5053-5762 & $3632-5052$ & $\leq 3631$ \\
\hline & $\mathrm{D}$ & $\geq 8.1$ & $8.1-7.1$ & $7.1-6.6$ & $6.6-5.5$ & $5.5-5.0$ & $5.0-4.0$ & $\leq 4.0$ \\
\hline & ND & $\geq 7.7$ & $7.7-6.7$ & $6.7-6.2$ & $6.2-5.2$ & $5.2-4.7$ & $4.7-3.7$ & $\leq 3.7$ \\
\hline & SUM & $\geq 15.7$ & $13.7-15.7$ & $12.8-13.7$ & $10.8-12.8$ & $9.8-10.8$ & 7.9-9.8 & $\leq 7.9$ \\
\hline & $\mathrm{D}$ & $\geq 56.7$ & $56.7-48.1$ & $48.1-43.8$ & $43.8-35.2$ & $35.2-30.9$ & $30.9-22.3$ & $\leq 22.3$ \\
\hline $\begin{array}{l}\text { RFD } \\
(\mathrm{N} / \mathrm{s} / \mathrm{l} g)\end{array}$ & ND & $\geq 53.5$ & $53.5-45.2$ & $45.2-41.1$ & $41.1-32.8$ & $32.8-28.7$ & $28.7-20.4$ & $\leq 20.4$ \\
\hline & SUM & $\geq 108.9$ & $92.7-108.9$ & $84.6-92.7$ & $68.4-84.6$ & $60.3-68.4$ & $44.0-60.3$ & $\leq 44.0$ \\
\hline Females & & & & & & & & \\
\hline & $\mathrm{D}$ & $\geq 398$ & $397-341$ & $340-312$ & $311-255$ & $254-227$ & $226-170$ & $\leq 169$ \\
\hline$F_{\max }$ & ND & $\geq 381$ & $380-323$ & $322-295$ & $294-237$ & 236-208 & $207-150$ & $\leq 149$ \\
\hline & SUM & $\geq 770.0$ & $769-660$ & $659-605$ & $604-495$ & $494-440$ & 439-330 & $\leq 329$ \\
\hline & $\mathrm{D}$ & $\geq 2805$ & 2804-2314 & 2313-2069 & 2068-1579 & 1578-1334 & 1333-843 & $\leq 842$ \\
\hline $\begin{array}{l}\mathrm{K} F \mathrm{D}_{\max } \\
(\mathrm{N} / \mathrm{s})\end{array}$ & ND & $\geq 2611$ & 2610-2146 & 2145-1914 & 1913-1449 & $1448-1217$ & 1216-753 & $\leq 752$ \\
\hline & SUM & $\geq 5336$ & 5335-4421 & $4420-3964$ & 3963-3048 & $3047-2591$ & $2590-1676$ & $\leq 1675$ \\
\hline & $\mathrm{D}$ & $\geq 6.2$ & $6.2-5.3$ & $5.3-4.8$ & $4.8-3.9$ & $3.9-3.5$ & $3.5-2.5$ & $\leq 2.5$ \\
\hline$(\mathrm{N} / \mathrm{kg})$ & ND & $\geq 6.0$ & $6.0-5.0$ & $5.0-4.6$ & $4.6-3.6$ & $3.6-3.2$ & $3.2-2.2$ & $\leq 2.2$ \\
\hline & SUM & $\geq 12.1$ & $12.1-10.3$ & $9.4-10.3$ & $7.6-9.4$ & $6.7-7.6$ & $4.9-6.7$ & $\leq 4.9$ \\
\hline & $\mathrm{D}$ & $\geq 43.6$ & $43.6-35.9$ & 35.9-32.0 & $32.0-24.3$ & $24.3-20.5$ & $20.5-12.8$ & $\leq 12.8$ \\
\hline$(\mathrm{N} / \mathrm{s} / \mathrm{kg})$ & ND & $\geq 40.5$ & $40.5-33.2$ & $33.2-29.6$ & $29.6-22.3$ & $22.3-18.7$ & $18.7-11.4$ & $\leq 11.4$ \\
\hline & SUM & $\geq 82.9$ & $68.5-82.9$ & $61.3-68.5$ & $46.9-61.3$ & $39.8-46.9$ & $25.4-39.7$ & $\leq 25.4$ \\
\hline
\end{tabular}

$\mathrm{F}_{\max }$ - maximal muscle force, $\mathrm{RFD}_{\max }$ - maximal explosive muscle force, $\mathrm{F}_{\text {rel }}$ - relative aspect of maximal muscle force, $\mathrm{RFD}_{\text {rel }}$ - relative aspect of maximal explosive muscle force, D - dominant hand, ND - non-dominant hand,

SUM - summarized for both hands
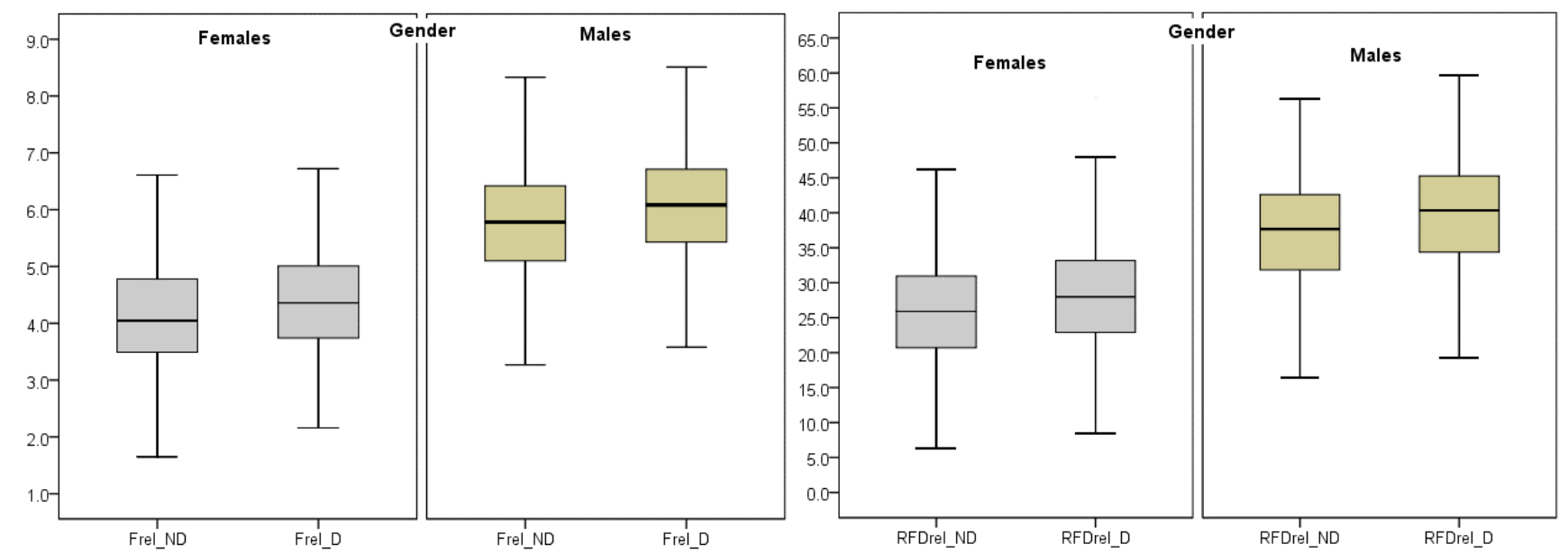

Figure 3. Boxplot distribution for the relative aspects of maximal muscle force $\left(\mathrm{F}_{\text {rel }}\right)$ and maximal explosive muscle force $\left(\mathrm{RFD}_{\mathrm{rel}}\right)$ for the dominant $(\mathrm{D})$ and non-dominant $(\mathrm{ND})$ hand among male and female subjects 
Table 3. Handgrip muscle force percentile standards for the observed variables by gender

\begin{tabular}{|c|c|c|c|c|c|c|c|c|c|c|c|c|c|}
\hline \multicolumn{2}{|c|}{ Percentiles } & 党 & $\hat{\mathrm{z}}_{\mathrm{J}}$ & 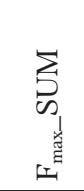 & 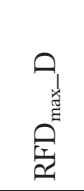 & 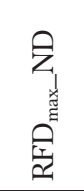 & 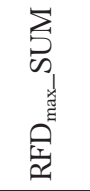 & $\theta_{1}^{\frac{1}{2}}$ & $\mathrm{Z}_{\frac{1}{2}}$ & 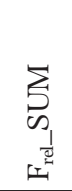 & 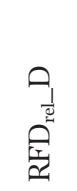 & 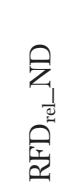 & 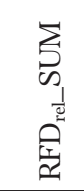 \\
\hline \multirow{9}{*}{$\begin{array}{l}\text { Males } \\
(n=444)\end{array}$} & 2.5 & 335 & 323 & 686 & 1672 & 1642 & 3527 & 4.0 & 3.7 & 8.1 & 20.8 & 18.4 & 40.3 \\
\hline & 5 & 367 & 350 & 722 & 2040 & 1852 & 3860 & 4.3 & 4.1 & 8.4 & 22.8 & 22.3 & 45.2 \\
\hline & 10 & 400 & 378 & 775 & 2314 & 2157 & 4482 & 4.8 & 4.3 & 9.2 & 28.4 & 26.4 & 54.5 \\
\hline & 30 & 466 & 441 & 915 & 3024 & 2751 & 5810 & 5.5 & 5.2 & 10.8 & 35.5 & 33.4 & 69.1 \\
\hline & 50 & 507 & 478 & 980 & 3395 & 3172 & 6603 & 6.1 & 5.8 & 11.9 & 40.4 & 37.7 & 78.6 \\
\hline & 70 & 562 & 522 & 1077 & 3746 & 3516 & 7229 & 6.5 & 6.3 & 12.8 & 44.2 & 41.6 & 85.1 \\
\hline & 90 & 631 & 599 & 1214 & 4219 & 3936 & 8029 & 7.3 & 6.9 & 14.1 & 49.4 & 47.1 & 95.0 \\
\hline & 95 & 676 & 636 & 1300 & 4560 & 4354 & 8701 & 7.6 & 7.2 & 14.6 & 51.9 & 49.7 & 100.0 \\
\hline & 97.5 & 719 & 659 & 1406 & 4946 & 4601 & 9605 & 8.2 & 7.7 & 16.0 & 56.0 & 52.8 & 106.8 \\
\hline \multirow{9}{*}{$\begin{array}{l}\text { Females } \\
(n=394)\end{array}$} & 2.5 & 191 & 165 & 367 & 929 & 821 & 1879 & 2.6 & 2.3 & 5.2 & 13.4 & 11.7 & 25.8 \\
\hline & 5 & 201 & 180 & 389 & 1079 & 930 & 2119 & 2.9 & 2.6 & 5.6 & 15.8 & 15.0 & 31.8 \\
\hline & 10 & 222 & 198 & 419 & 1246 & 1099 & 2378 & 3.2 & 2.9 & 6.2 & 18.3 & 16.9 & 36.2 \\
\hline & 30 & 252 & 233 & 490 & 1577 & 1452 & 3060 & 3.9 & 3.6 & 7.5 & 24.2 & 21.7 & 46.1 \\
\hline & 50 & 277 & 261 & 539 & 1787 & 1661 & 3463 & 4.4 & 4.0 & 8.4 & 28.1 & 25.9 & 53.6 \\
\hline & 70 & 310 & 292 & 595 & 2030 & 1857 & 3866 & 4.8 & 4.7 & 9.4 & 31.8 & 30.1 & 61.2 \\
\hline & 90 & 352 & 330 & 682 & 2423 & 2234 & 4587 & 5.7 & 5.3 & 10.9 & 38.1 & 35.9 & 72.9 \\
\hline & 95 & 381 & 358 & 738 & 2707 & 2397 & 4993 & 5.9 & 5.6 & 11.5 & 40.2 & 37.7 & 76.7 \\
\hline & 97.5 & 430 & 399 & 819 & 2962 & 2905 & 5826 & 6.3 & 5.9 & 11.9 & 43.9 & 40.6 & 81.4 \\
\hline
\end{tabular}

$\mathrm{F}_{\max }$ - maximal muscle force, $\mathrm{RFD}_{\max }$ - maximal explosive muscle force, $\mathrm{F}_{\text {rel }}$ - relative aspect of maximal muscle force, $\mathrm{RFD}_{\text {rel }}$ - relative aspect of maximal explosive muscle force, D - dominant hand, ND - non-dominant hand,

SUM - summarized for both hands

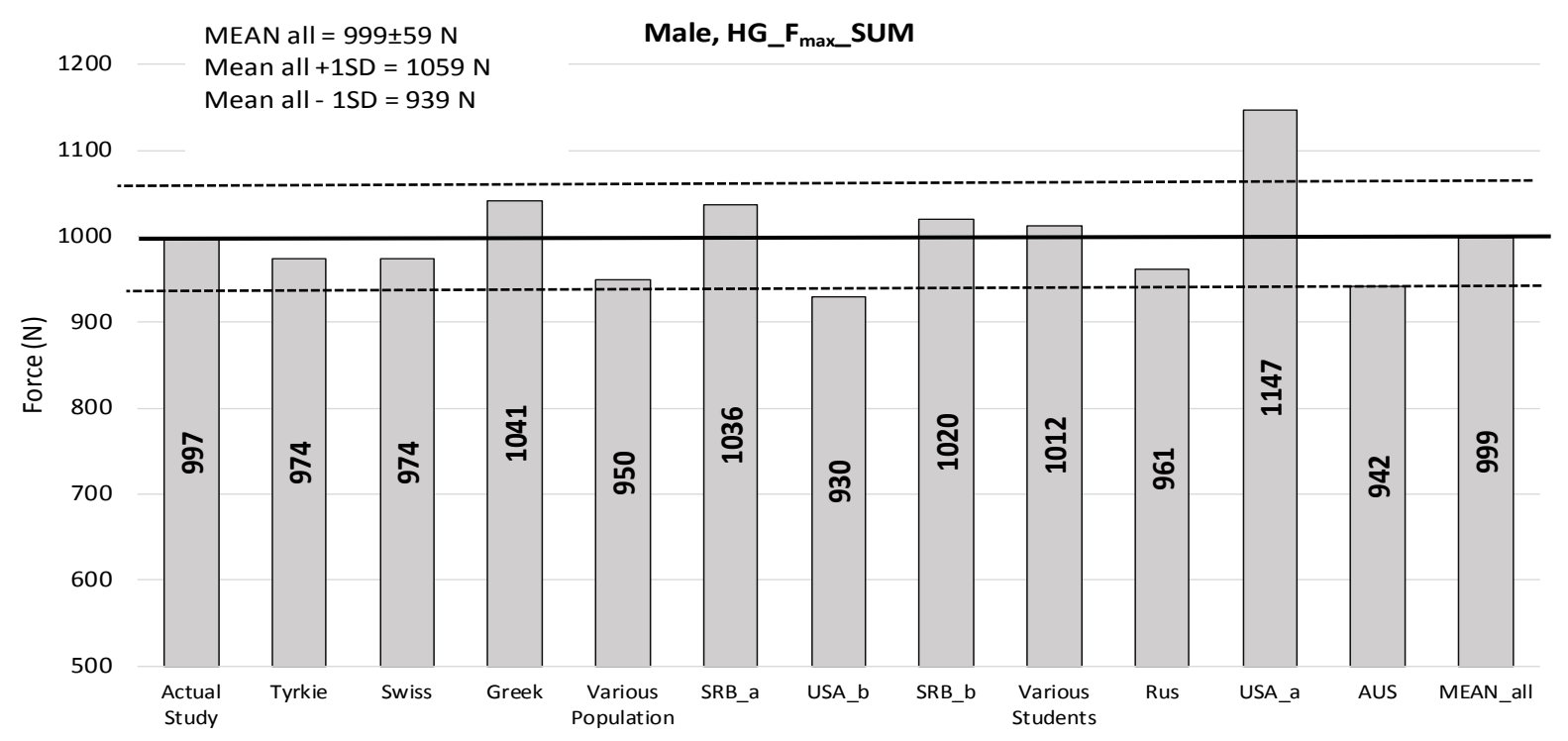

Data adopted from: Werle et al. [32], Mitsionis et al. [33], Hogrel [34], Eksioglu [35], Perna et al. [6], Marković et al. [27], Wang et al. [24], Dopsaj et al. [5], Wang et al. [36], Marković et al. [20].

Figure 4. External validation data for handgrip $(\mathrm{HG})$ summarized maximal muscle force ( $\left.\mathrm{F}_{\max } \mathrm{SUM}\right)$ for male subjects 


\section{HUMAN MOVEMENT}

M. Dopsaj et al., Global handgrip test normative data

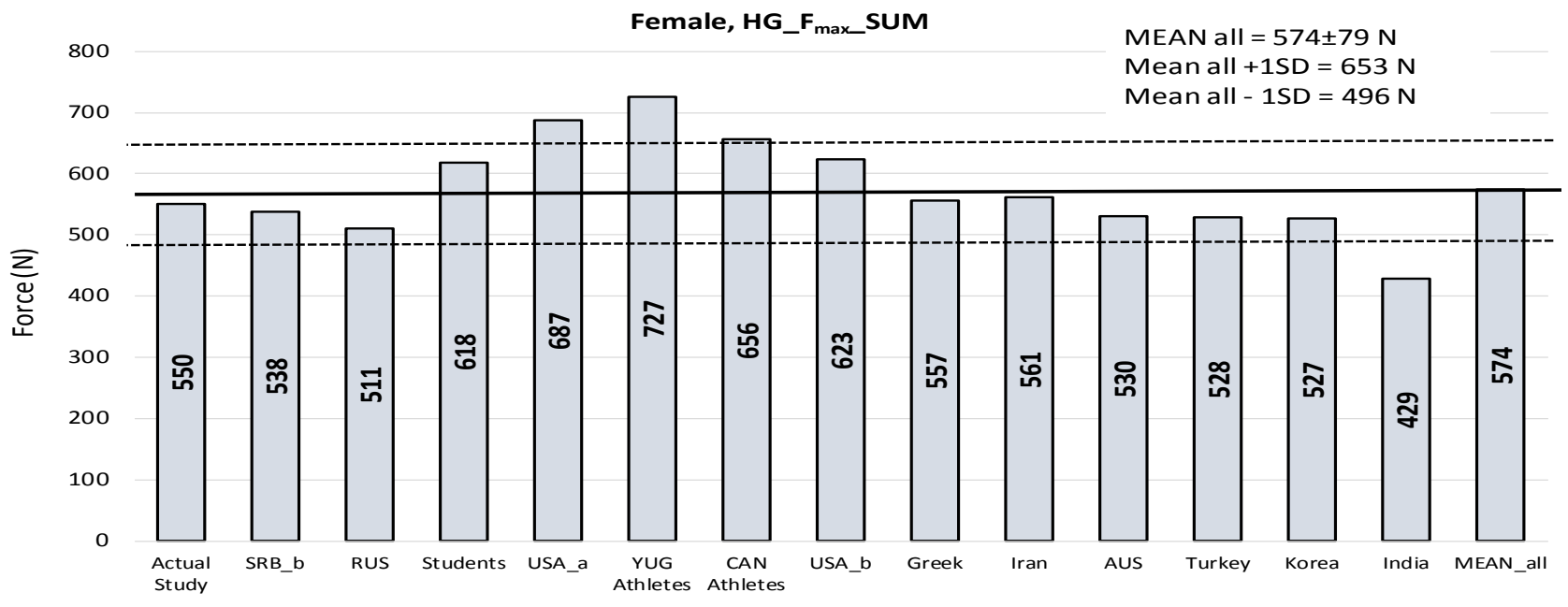

Data adopted from: Keogh et al. [37], Koley et al. [38], Mitsionis et al. [33], Ivanović and Dopsaj [39], Mohammadian et al. [40], Hogrel [34], Eksioglu [35], Perna et al. [6], Wang et al. [24], Zaric et al. [4], Dopsaj et al. [5], Wang et al. [36].

Figure 5. External validation data for handgrip $(\mathrm{HG})$ summarized maximal muscle force $\left(\mathrm{F}_{\mathrm{max}-} \mathrm{SUM}\right)$ for female subjects

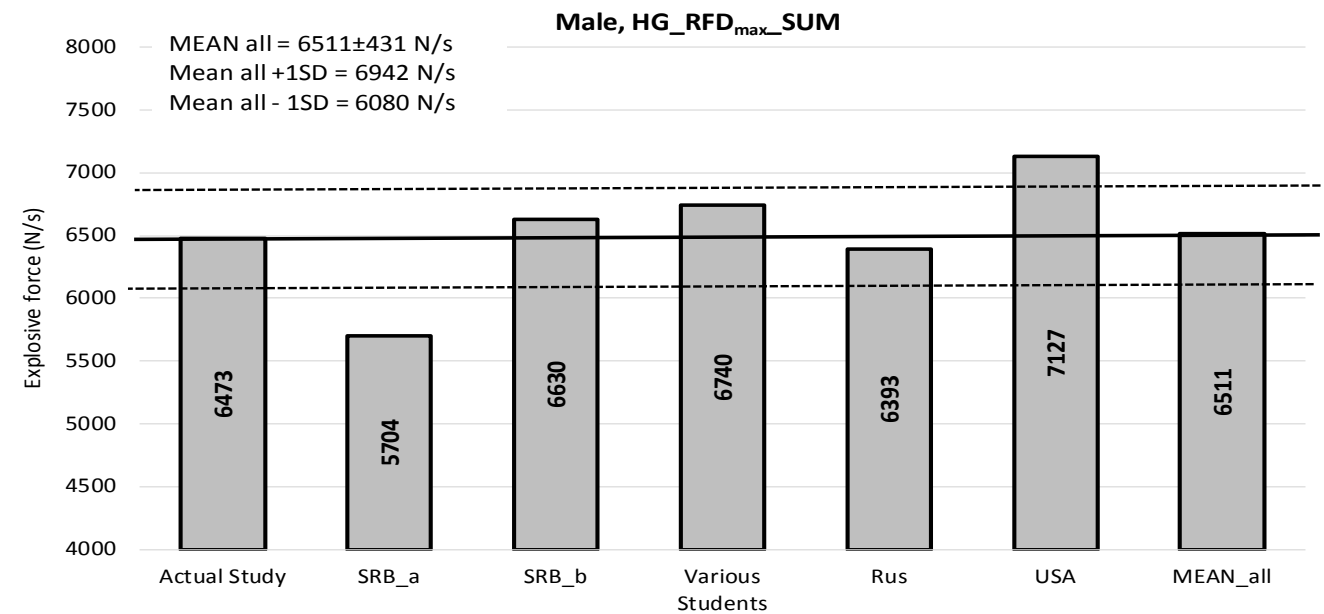

Data adopted from: Hogrel [34], Perna et al. [6], Dopsaj et al. [8], Marković et al. [27], Wang et al. [24], Dopsaj et al. [5], Wang et al. [36].

Figure 6. External validation data for handgrip (HG) summarized maximal explosive muscle force (RFD max_$_{-} \mathrm{SUM}_{\mathrm{N}}$ for male subjects

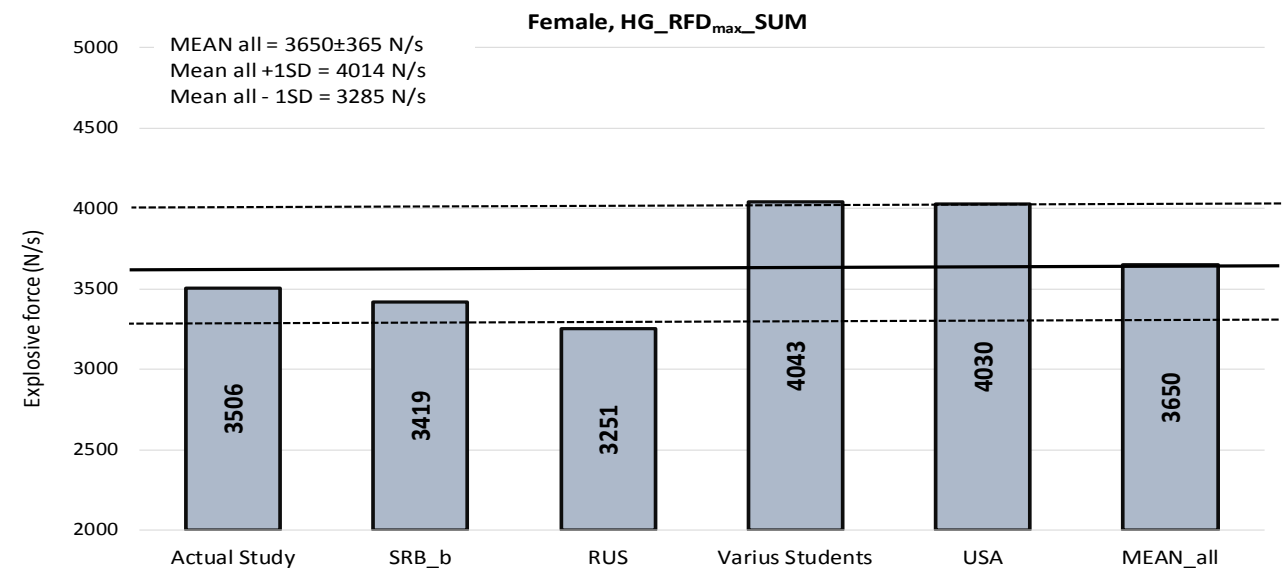

Data adopted from: Perna et al. [6], Wang et al. [24], Zaric et al. [4], Dopsaj et al. [5], Wang et al. [36].

Figure 7. External validation data for handgrip (HG) summarized maximal explosive muscle force (RFD ${ }_{\text {max }}$ SUM) for female subjects 
mean value for maximal explosive handgrip strength for an adult female was $3506 \pm 915 \mathrm{~N} / \mathrm{s}$ (1858.3 and 1681.7 for the dominant and non-dominant hand, respectively) as an absolute and $54.13 \pm 14.38 \mathrm{~N} / \mathrm{s} / \mathrm{kg}$ (28.7 and 26.0 for the dominant and non-dominant hand, respectively) as a relative measure.

With reference to the parameters of homogeneity and accuracy of measurement, it can be concluded that the data can be accepted as homogeneous (because the coefficient of variation was between $16.4 \%$ and $26.9 \%$ ) (Table 1).

In the general Australian population, Egger et al. [41] suggest that the average sum for male handgrip strength was $96 \mathrm{~kg}(942 \mathrm{~N})$, while the average sum for females was $54 \mathrm{~kg}(530 \mathrm{~N})$. Wang et al. [24, 36] found that the handgrip isometric strength obtained from dominant and non-dominant hands of male and female participants equalled $93.8 \mathrm{~kg}(919.8 \mathrm{~N})$ and $59 \mathrm{~kg}(578.5 \mathrm{~N})$, respectively. Both studies indicated scores below the present results, but still in line with the normal standard range of normative handgrip data.

Comparing with the results of other studies $[3,5$, $6,9,10,24,25,27,32-34,36-41]$ which were performed with the same measurement method, genders, and ages, it can be confirmed that the external validity of our results is acceptable because the average values for the variables of $\mathrm{F}_{\max } \mathrm{SUM}$ and $\mathrm{RFD}_{\max } \mathrm{SUM}$ are in the range of one standard deviation from the previously published findings (Figures 4-7). Still, there are no suitable studies which would investigate the observed handgrip strength contractile characteristics in the relative aspect (dependent on body mass), so, unfortunately, the current data cannot be externally validated.

However, considering the values of the index of gender dimorphism (Figures 2 and 3 ) as the ratio of measured variables between sexes [42], it can be stated that the results for the variables of $F_{\text {max }} S U M, R_{\text {max }} S U M$, $\mathrm{F}_{\text {rel_}} \mathrm{SUM}$, and $\mathrm{RFD}_{\text {rel_}} \mathrm{SUM}$ in females were at the level of 0.552 (55.2\%), 0.542 (54.2\%), 0.721 (72.1\%), and $0.708(70.8 \%)$ as compared with men, respectively. In other words, men were absolutely and relatively stronger and more explosive than women at the ratio of $1.81,1.85,1.39$, and 1.41 , respectively.

Overall, considering the handgrip normative data for the general population of healthy adults, it can be concluded that we can accept the following standard (average) values of maximal and explosive strength: $\mathrm{F}_{\text {max }} \mathrm{SUM}$ of 910-1084 N and 495-604 N, as well as $\mathrm{RFD}_{\text {max }} \mathrm{SUM}$ of $5763-7182 \mathrm{~N} / \mathrm{s}$ and 3048-3963 N/s for males and females, respectively (Table 1). As for the relative handgrip strength aspect, the following standard values can be accepted: $\mathrm{F}_{\text {rel__SUM of } 10.8-}$ $12.75 \mathrm{~N} / \mathrm{kg}$ and $7.60-9.38 \mathrm{~N} / \mathrm{kg}$, as well as RFD rel_SUM $_{1}$ of $68.37-84.58 \mathrm{~N} / \mathrm{s} / \mathrm{kg}$ and $46.94-61.32 \mathrm{~N} / \mathrm{s} / \mathrm{kg}$ for males and females, respectively (Table 2).

Also, the results imply that the relative values of measurement errors, expressed as the average for the dominant and non-dominant hand and calculated as (standard error of the mean $/$ mean) $\times 100$, for the strength characteristics determined in the handgrip test by using a measuring instrument, were very small. They equalled $0.86 \%$ and $1.08 \%$ in the male sample and $1.06 \%$ and $1.28 \%$ in the female sample for $F_{\max }$ and $\mathrm{RFD}_{\max }$, respectively (Table 1 ). This proves that the accuracy of the applied measurement method and instrument is very high, which allows the conclusion that the obtained data are valid for scientific interpretation.

Thus, we can infer that humans, who can be characterized as extremely handgrip strong individuals (Table 2), can achieve an $\mathrm{F}_{\text {max }} \mathrm{SUM}$ and $\mathrm{RFD}_{\max }$ SUM greater than $1349 \mathrm{~N}((\geq 703 \mathrm{~N}$ for the dominant and $(\geq 658 \mathrm{~N}$ for the non-dominant hand) and greater than $9314 \mathrm{~N} / \mathrm{s}(\geq 4863 \mathrm{~N} / \mathrm{s}$ for the dominant and $\geq 4559 \mathrm{~N} / \mathrm{s}$ for the non-dominant hand) in males, and greater than $770 \mathrm{~N}(\geq 398 \mathrm{~N}$ for the dominant and $\geq 381 \mathrm{~N}$ for the non-dominant hand) and greater than $5336 \mathrm{~N} / \mathrm{s}(\geq 2805 \mathrm{~N} / \mathrm{s}$ for the dominant and $\geq 2611 \mathrm{~N} / \mathrm{s}$ for the non-dominant hand) in females. However, if a person cannot produce more than 7.9 or $4.9 \mathrm{~N} / \mathrm{kg}$ of relative strength value or more than 44.0 or $25.4 \mathrm{~N} / \mathrm{s} / \mathrm{kg}$ of relative explosive strength value as a sum of left and right handgrip results, according to the actual normative data, they can be classified as a very weak handgrip individual (male or female, respectively; Table 2).

The analogue normative scale, expressed in percentile distribution standards (Table 3), showed very similar cut-off zones, which implies that both types of data can be used, depending on the chosen classification methodology.

\section{Conclusions}

On the basis of the parameters of homogeneity and accuracy of measurement, it can be concluded that the data can be recognized as homogeneous and as accurate, which means that the suggested nominal normative values can be accepted with a high level of internal validity, regardless of gender. When comparing the findings with the results of other studies which were performed with the same measurement method, genders, and ages, it can be confirmed that the external validity of our results is highly acceptable because the average values for the variables of $\mathrm{F}_{\text {max }} \mathrm{SUM}$ and 
$\mathrm{RFD}_{\max } \mathrm{SUM}$ are in the range of one standard deviation from the previously published, i.e. scientifically validated findings.

A study of this type presents the permanently valid level of interest of the scientific research to increase the fundamentals of knowledge and to perfect the testing procedures in health diagnostics, therapy, rehabilitation, and sports. The normative reference values provided in this study may serve as an international guide for interpreting grip strength measurements obtained from tested individuals.

\section{Acknowledgements}

This paper is a part of the project 'Effects of the Applied Physical Activity on Locomotor, Metabolic, Psychosocial and Educational Status of the Population of the Republic of Serbia,' number III47015, funded by the Ministry of Education, Science and Technological Development of the Republic of Serbia - Scientific Projects 2011-2019 Cycle.

\section{Disclosure statement}

No author has any financial interest or received any financial benefit from this research.

\section{Conflict of interest}

The authors state no conflict of interest.

\section{References}

1. Almécija S, Smaers JB, Jungers WL. The evolution of humans and ape hand proportions. Nat Commun. 2015; 6:7717; doi: 10.1038/ncomms8717.

2. McMillan IR, Carin-Levy G. Tyldesley \& Grieve’s muscles, nerves and movement in human occupation, $4^{\text {th }}$ ed. Oxford: Wiley-Blackwell; 2012.

3. Orr R, Pope R, Stierli M, Hinton B. Grip strength and its relationship to police recruit task performance and injury risk: a retrospective cohort study. Int J Environ Res Public Health. 2017;14(8):941; doi: 10.3390/ijerph14080941.

4. Zarić I, Dopsaj M, Marković M. Match performance in young female basketball players: relationship with laboratory and field tests. Int J Perform Anal Sport. 2018; 18(1):90-103; doi: 10.1080/24748668.2018.1452109.

5. Dopsaj M, Nenasheva AV, Tretiakova TN, Syromiatnikova YA, Surina-Marysheva EF, Marković S, et al. Handgrip muscle force characteristics with general reference values at Chelyabinsk and Belgrade students. Human Sport Med. 2019;19(2):27-36; doi: 10.14529/hsm190204.

6. Perna FM, Coa K, Troiano RP, Lawman HG, Wang C-Y, Li Y, et al. Muscular grip strength estimates of the U.S. population from the National Health and Nutrition Examination Survey 2011-2012. J Strength Cond Res. 2016;30(3):867-874; doi: 10.1519/JSC.00000000000 01104 .
7. Trajkov M, Cuk I, Eminovic F, Kljajic D, Dopsaj M. Relationship between hand grip strength and endurance and postural stability in active and sedentary older women. J Electromyogr Kinesiol. 2018;43:62-67; doi: 10.1016/j.jelekin.2018.09.006.

8. Dopsaj M, Mijalkovski Z, Vasilovski N, Ćopić N, Brzaković M, Marković M. Morphological parameters and handgrip muscle force contractile characteristics in the first selection level in water polo: differences between U15 water polo players and the control group. Human Sport Med. 2018;18(3):5-15; doi: 10.14529/hsm180301.

9. Dopsaj M, Umek T, Kos A. Relation between hand grip contractile characteristics and simple fast arm movement measured by IMU sensors. In: Stojiljkovic N (ed.), FIS Communications 2019 book of proceedings. Niš: Faculty of Sport and Physical Education, University of Niš; 2019; 263-267.

10. Luna-Heredia E, Martín-Peña G, Ruiz-Galiana J. Handgrip dynamometry in healthy adults. Clin Nutr. 2005; 24(2):250-258; doi: 10.1016/j.clnu.2004.10.007.

11. Wind AE, Takken T, Helders PJM, Engelbert RHH. Is grip strength a predictor for total muscle strength in healthy children, adolescents, and young adults? Eur J Pediatr. 2010;169(3):281-287; doi: 10.1007/s00431009-1010-4.

12. Sayer AA, Kirkwood TBL. Grip strength and mortality: a biomarker of ageing? Lancet. 2015;386(9990):226227; doi: 10.1016/S0140-6736(14)62349-7.

13. Amato A, Baldassano S, Cortis C, Cooper J, Proia P. Physical activity, nutrition, and bone health. Hum Mov. 2018;19(4):1-10; doi: 10.5114/hm.2018.77318.

14. Neidenbach RC, Oberhoffer R, Pieper L, Freilinger S, Ewert P, Kaemmerer H, et al. The value of handgrip strength (HGS) as a diagnostic and prognostic biomarker in congenital heart disease. Cardiovasc Diagn Ther. 2019;9(Suppl. 2):187-197; doi: 10.21037/cdt.2019.09.16.

15. Smith L, Firth J, Grabovac I, Koyanagi A, Veronese N, Stubbs B, et al. The association of grip strength with depressive symptoms and cortisol in hair: a cross-sectional study of older adults. Scand J Med Sci Sports. 2019; 29(10):1604-1609; doi: 10.1111/sms.13497.

16. Halaweh H. Correlation between health-related quality of life and handgrip strength among older adults. Exp AgingRes.2020;46(2):178-191;doi:10.1080/0361073X. 2020.1716157.

17. Aagaard P, Simonsen EB, Andersen JL, Magnusson P, Dyhre-Poulsen P. Increased rate of force development and neural drive of human skeletal muscle following resistance training. J Appl Physiol. 2002;93(4):13181326; doi: 10.1152/japplphysiol.00283.2002.

18. Maffiuletti N, Aagaard P, Blazevich AJ, Folland J, Tillin N, Duchateau J. Rate of force development: physiological and methodological considerations. Eur J Appl Physiol. 2016;116(6):1091-1116; doi: 10.1007/s00421016-3346-6.

19. Cooper R, Kuh D, Cooper C, Gale CR, Lawlor DA, Matthews F, et al. Objective measures of physical capability 
and subsequent health: a systematic review. Age Ageing. 2011;40(1):14-23; doi: 10.1093/ageing/afq117.

20. Marković S, Dopsaj M, Veljković V. Reliability of Sports Medical Solutions handgrip and Jamar handgrip dynamometer. Meas Sci Rev. 2020;20(2):59-64; doi: 10.2478/msr-2020-0008.

21. Aadahl M, Beyer N, Linneberg A, Heinsbæk Thuesen B, Jørgensen T. Grip strength and lower limb extension power in 19-72-year-old Danish men and women: the Health 2006 study. BMJ Open. 2011;1(2):e000192; doi: 10.1136/bmjopen-2011-000192.

22. Dodds RM, Syddall HE, Cooper R, Benzeval M, Deary IJ, Dennison EM, et al. Grip strength across the life course: normative data from twelve British studies. PLoS One. 2014;9(12):e113637; doi: 10.1371/journal.pone.0113637.

23. Mendes J, Amaral TF, Borges N, Santos A, Padrão P, Moreira P, et al. Handgrip strength values of Portuguese older adults: a population based study. BMC Geriatr. 2017;17(1):191; doi: 10.1186/s12877-017-0590-5.

24. Wang Y-C, Bohannon RW, Li X, Sindhu B, Kapellusch J. Hand-grip strength: normative reference values and equations for individuals 18 to 85 years of age residing in the United States. J Orthop Sports Phys Ther. 2018;48(9):672-734; doi: 10.2519/jospt.2018.7851.

25. Borges LS, Fernandes MH, Schettino L, da Silva Coqueiro R, Pereira R. Handgrip explosive force is correlated with mobility in the elderly women. Acta Bioeng Biomech. 2015;17(3):145-149; doi: 10.5277/ABB-001242014-03.

26. Christie B. Doctors revise Declaration of Helsinki. BMJ. 2000;321(7266):913; doi: 10.1136/bmj.321.7266.913.

27. Marković MR, Dopsaj M, Koropanovski N, Ćopić N, Trajkov M. Reliability of measuring various contractile functions of finger flexors of men of various ages. Phys Cult. 2018;72(1):37-48; doi: 10.5937/fizkul1801037M.

28. Knezevic OM, Mirkov DM, Kadija M, Nedeljkovic A, Jaric S. Asymmetries in explosive strength following anterior cruciate ligament reconstruction. Knee. 2014; 21(6):1039-1045; doi: 10.1016/j.knee.2014.07.021.

29. Zatsiorsky V. Sports metrology [in Russian]. Moscow: Physical Education and Sports; 1982.

30. Bucher JL (ed.). The metrology handbook, $2^{\text {nd }}$ ed. Milwaukee: ASQ Quality Press; 2012.

31. Hair JF, Black WC, Babin BJ, Anderson RE. Multivariate data analysis. Edinburg: Pearson Education Limited; 2014.

32. Werle S, Goldhahn J, Drerup S, Simmen BR, Sprott H, Herren DB. Age- and gender-specific normative data of grip and pinch strength in a healthy adult Swiss population. J Hand Surg Eur Vol. 2009;34(1):76-84; doi: 10.1177/1753193408096763.

33. Mitsionis G, Pakos EE, Stafilas KS, Paschos N, Papakostas T, Beris AE. Normative data on hand grip strength in a Greek adult population. Int Orthop. 2009;33(3): 713-717; doi: 10.1007/s00264-008-0551-x.

34. Hogrel J-Y. Grip strength measured by high precision dynamometry in healthy subjects from 5 to 80 years.
BMC Musculoskelet Disord. 2015;16:139; doi: 10.1186/ s12891-015-0612-4.

35. Ekşioğlu M. Normative static grip strength of population of Turkey, effects of various factors, and a comparison with international norms. Appl Ergon. 2016;52:8-17; doi: 10.1016/j.apergo.2015.06.023.

36. Wang Y-C, Bohannon RW, Li X, Yen S-C, Sindhu B, Kapellusch J. Summary of grip strength measurements obtained in the 2011-2012 and 2013-2014 National Health and Nutrition Examination Surveys. J Hand Ther. 2019;32(4):489-496; doi: 10.1016/j.jht.2018.03. 002 .

37. Keogh JWL, Weber CL, Dalton CT. Evaluation of anthropometric, physiological, and skill-related tests for talent identification in female field hockey. Can J Appl Physiol. 2003;28(3):397-409; doi: 10.1139/h03-029.

38. Koley S, Kaur N, Sandhu JS. A study on hand grip strength in female labourers of Jalandhar, Punjab, India. J Life Sci. 2009;1(1):57-62; doi: 10.1080/09751270. 2009.11885135

39. Ivanović J, Dopsaj M. Functional dimorphism and characteristics of maximal hand grip force in top level female athletes. Coll Antropol. 2012;36(4):1231-1240.

40. Mohammadian M, Choobineh A, Haghdoost A, Hasheminejad N. Normative data of grip and pinch strengths in healthy adults of Iranian population. Iran J Public Health. 2014;43(8):1113-1122.

41. Egger G, Champion N, Bolton A. The fitness leader's handbook. Kenthurst: Kangaroo Press; 1999.

42. Lovich JE, Gibbons JW. A review of techniques for quantifying sexual size dimorphism. Growth Dev Aging. 1992;56(4):269-281. 